\title{
Use of a stochastic simulation model to estimate the cost per case of digital dermatitis, sole ulcer, and white line disease by parity group and incidence timing
}

\author{
K. A. Dolecheck, ${ }^{1 *}$ M. W. Overton, ${ }^{2}$ T. B. Mark, ${ }^{3}$ and J. M. Bewley ${ }^{4}$ \\ ${ }^{1}$ Department of Animal and Food Sciences, University of Kentucky, Lexington 40546 \\ 2Elanco Animal Health, 2500 Innovation Way, Greenfield, IN 46140 \\ ${ }^{3}$ Department of Agricultural Economics, University of Kentucky, Lexington 40546 \\ ${ }^{4}$ Alltech Inc., 3031 Catnip Hill Rd., Nicholasville, KY 40356
}

\section{ABSTRACT}

A farm-level stochastic simulation model was modified to estimate the cost per case of 3 foot disorders (digital dermatitis, sole ulcer, and white line disease) by parity group and incidence timing. Disorder expenditures considered within the model included therapeutics, outside labor, and on-farm labor. Disorder losses considered within the model included discarded milk, reduced milk production, extended days open, an increased risk of culling, an increased risk of death (natural or euthanized), and disease recurrence. All estimates of expenditures and losses were defined using data from previously published research in stochastic distributions. Stochastic simulation was used to account for variation within the farm model; 1,000 iterations were run. Sensitivity of foot disorder costs to selected market prices (milk price, feed price, replacement heifer price, and slaughter price) and herd-specific performance variables (pregnancy rate) were analyzed. Using our model assumptions, the cost per disorder case over all combinations of parity group and incidence timing, regardless of incidence likelihood, was lowest for digital dermatitis ( $\$ 64 \pm 24$; mean \pm standard deviation), followed by white line disease $(\$ 152 \pm 26)$ and sole ulcer $(\$ 178 \pm 29)$. Disorder costs were greater in multiparous versus primiparous cows and were always highest at the beginning of lactation. The greatest contributing cost categories were decreased milk production, an increased risk of culling, and disease recurrence. The contribution of cost categories to the total cost of disorder varied by disorder type, parity group, and incidence timing. For all disorders, the cost per case increased as milk price or replacement heifer price increased and decreased as feed price, pregnancy rate, or slaughter price increased.

Received April 9, 2018.

Accepted September 15, 2018.

*Corresponding author: karmella.dolecheck@uky.edu
Understanding how foot disorder costs change according to cow-specific conditions (i.e., disorder type, parity group, and days in milk at incidence) and herd-specific conditions (i.e., market prices and performance variables) can help improve on-farm decisions about treatment and prevention of foot disorders.

Key words: lameness, disease cost, hoof health, animal health economics

\section{INTRODUCTION}

Lameness is a widespread issue in the dairy industry, with prevalence ranging from 5.5 to $70.1 \%$ (mean = $27.2 \%$ ) on United States and Canadian dairy farms (Costa et al., 2017). Although commonly referred to as a disease itself, lameness is actually a clinical sign often associated with different foot disorders. Each case of lameness, and the associated foot disorder causing it, is associated with both direct expenditures (e.g., onfarm labor, hoof trimmer labor, and therapeutics) and indirect losses (e.g., discarded milk, reduced milk production, reduced reproductive performance, increased risk of death, increased risk of culling, and disease recurrence; Dolecheck and Bewley, 2018). Understanding the total cost per foot disorder case is valuable for improving management at both the cow and herd level by aiding in the selection of lameness treatment strategies, culling strategies, and prevention investments.

Most previous lameness cost estimates have focused on either the cost of lameness at the herd level (Kaneene and Hurd, 1990; Miller and Dorn, 1990), the cost per case of nonspecific lameness (Harris et al., 1988; Guard, 2008; Liang et al., 2017), or the cost per case of lameness categorized as interdigital, digital, or sole ulcer (Esslemont and Peeler, 1993; Kossaibati and Esslemont, 1997; Esslemont, 2005). More recently, specific foot disorders have been considered when calculating the cost per case of lameness (Willshire and Bell, 2009; Bruijnis et al., 2010; Cha et al., 2010; Charfeddine and 
Pérez-Cabal, 2017); however, Dolecheck and Bewley (2018) highlighted that these costs often still fail to consider how case-specific factors, including parity and incidence timing relative to calving, affect the cost of each disorder, even though previous literature supports that these differences exist. Liang et al. (2017) found that the total cost per case of nonspecific lameness was 1.8 times greater in multiparous cows than primiparous cows. Those authors attributed most of the difference to increased multiparous cow losses associated with reduced milk yield, culling, and extended days open. Booth et al. (2004) demonstrated how the effect of foot disorders on survival differed depending on disorder diagnosis timing. Logically, incidence timing would also influence discarded milk and reduced milk production because of yield changes throughout lactation and reduced reproductive performance, assuming a reduced effect of lameness on reproduction after pregnancy is established.

The objective of our study was to build a stochastic simulation model capable of estimating foot disorder costs depending on disorder type, parity group, and incidence timing. Other studies (Ettema and Østergaard, 2006; Bruijnis et al., 2010; Liang et al., 2017) have also used stochastic simulation to estimate disease costs, which allows evaluation of how disease costs change with variation in farm- and market-specific values. To demonstrate usefulness, the model was used to calculate the cost per case of digital dermatitis, sole ulcer, and white line disease in an example United States dairy herd.

\section{MATERIALS AND METHODS}

\section{Model Overview}

A pre-existing farm-level, Monte Carlo simulation model was adapted for use in our study (Bewley et al., 2010; Liang et al., 2017). The model was created using Excel 2016 (Microsoft Corp., Redmond, WA) and stochastic features were applied using the @Risk addin (Version 7, Palisade Corporation, Ithaca, NY). As described previously by Liang et al. (2017), the model worked by calculating the milk yield [estimated via the lactation curve described by Skidmore (1990)], BW, DMI [estimated via equations found in NRC (2001)], and pregnancy status of the average cow in the herd every day for 6 parities. The average cow was assumed to represent all cows in the herd and information about the cow was used to calculate disorder costs. The Monte Carlo simulation method is a technique that allows rerunning of a simulation model repeatedly while key variables vary stochastically. When a variable was modeled stochastically, a distribution was defined for that variable based on previously published literature or industry averages. During each iteration of the model, a different value from that distribution was selected for use. For our study, variables assumed to influence the cost of lameness were modeled stochastically, resulting in unique cost per case estimates for each foot disorder each time the model was run. All stochastic variables, except market prices (described below), were independent from one another.

\section{Disorder Case Definitions}

For our study, 3 foot disorders were selected for modeling: digital dermatitis, sole ulcer, and white line disease. These conditions were selected because they are considered the most prevalent lameness causing disorders in United States dairy herds (DeFrain et al., 2013). Additionally, these 3 foot disorders had the most published data available to be able to specify costs by parity group and incidence timing. Two parity groups were selected for inclusion: primiparous and multiparous. To evaluate how incidence timing affected the cost of disorders, 4 incidence periods were selected: 0 to 60,61 to 120,121 to 240 , and >240 DIM. These incidence timings were selected from Booth et al. (2004), who reported culling risk associated with different foot disorders by incidence timing.

\section{Calculation of Lameness Expenditures and Losses}

The expenditures and losses associated with lameness were recently reviewed in Dolecheck and Bewley (2018). For our study, only losses and expenditures with enough data to estimate for individual foot disorders were incorporated, as determined by the authors. Modeled expenditures included outside (hoof trimmer) labor, therapeutics, and on-farm labor. Modeled losses included discarded milk, reduced milk production, extended days open, an increased risk of culling, an increased risk of death (natural or euthanized), and disease recurrence. Other potential cost categories that were not included were costs associated with decreased animal welfare and costs associated with other diseases resulting from lameness. All expenditure and loss categories were calculated individually for each combination of disorder type (digital dermatitis, sole ulcer, or white line disease), parity group (primiparous or multiparous), and incidence timing (0 to 60, 61 to 120,121 to 240 , or $>240$ DIM) for a total of 24 lameness case cost estimates. The total cost per case was the sum of all individual loss and expenditure categories. Separate modules within the model were used to calculate each cost category and necessary precursors for those categories. 
Market Prices Module. Current market prices (milk price, feed price, slaughter price, and replacement heifer price) were necessary to accurately calculate many of the disorder-related losses. Historical price variation and future price baseline data were used to create stochastic predicted prices for 2018, similar to the process described by Bewley et al. (2010) and Liang et al. (2017). To summarize, historical prices from the past $10 \mathrm{yr}$ were used to create simulated error terms that could be added to the expected 2018 price to account for variation in the prediction. Additionally, a correlation matrix between historical values over the past $10 \mathrm{yr}$ was implemented to prevent unrealistic price combinations (e.g., high corn price and low soybean price).

Annual historical United States prices for milk, alfalfa, corn, soybean, slaughter cows, and replacement heifers from the previous $10 \mathrm{yr}$ (2008 to 2017) were collected from the Understanding Dairy Markets website (Gould and Bozic, 2018). The expected 2018 prices for milk, alfalfa, corn, soybean, and slaughter price were collected from US Baseline Briefing Book: Projections for Agricultural and Biofuel Markets (FAPRI, 2018). Feed price was subsequently estimated from corn, soybean, and alfalfa prices using the equation published by Bailey and Ishler (2007). Because no market predictions for replacement heifer price were identified, the expected 2018 replacement heifer price was assumed identical to the observed 2017 replacement heifer price, as reported by the Understanding Dairy Markets website (Gould and Bozic, 2018).

Retention Pay-Off Module. The stochastic market prices and the daily simulated cow data (i.e., milk yield, BW, DMI, and pregnancy status) were combined to calculate the retention pay-off (RPO) value for every day over the lifetime of the average cow. Retention pay-off compares the value of the current cow with her potential replacement, considering both cows' expected future profits based on daily revenues (milk sales, calf value, and slaughter value) and costs (feed costs, veterinary costs, breeding costs, and probability of mortality). The RPO value represents a cow's worth beyond her slaughter value and can be used to estimate losses resulting from early or nonoptimal culling and death (Groenendaal et al., 2004). For additional details regarding how RPO is calculated, see Groenendaal et al. (2004). In this model, the RPO value was used in the calculation of losses associated with extended days open and an increased risk of culling.

Treatment Module. The treatment module calculated expenditures associated with outside labor, onfarm labor, and therapeutics and the losses associated with discarded milk. Expenditures on outside labor, on-farm labor, and therapeutics were disorder-specific and losses associated with discarded milk were disorder type-, parity group-, and incidence timing-specific. Estimates used in the model for outside labor and therapeutics were taken from a survey of hoof trimmers and veterinarians conducted by Dolecheck et al. (2018; Table A1). The responses from hoof trimmers $(\mathrm{n}=90$ for digital dermatitis; $n=88$ for sole ulcer and white line disease) to questions about the amount charged to a producer for labor and supplies per case by disorder type were used to create stochastic distributions for disorder-specific outside labor and therapeutic costs per case. This data set was evaluated using the distribution fitting feature in @Risk, and the best distribution was identified using the Akaike information criterion value. An extreme values distribution, related to the Weibull distribution, was chosen to represent therapeutic costs associated with sole ulcer treatment. All other distributions for both outside labor and therapeutics were log logistic distributions. Log logistic distributions are similar in shape to log-normal distributions but have thicker tails. All distributions were truncated at a minimum of 0 , meaning if a value less than 0 was drawn from the distribution, the distribution was resampled assuming there would never be decreased costs associated with outside labor or therapeutics resulting from a foot disorder case. Outside labor and therapeutic expenditures were assumed to be identical regardless of parity group and incidence timing.

Charfeddine and Pérez-Cabal (2017) reported the mean cost of on-farm labor per mild and severe case of digital dermatitis, sole ulcer, and white line disease. These means were weighted by the observed severity incidence levels in Charfeddine and Pérez-Cabal (2017) to estimate the mean cost of on-farm labor by disorder type, regardless of severity. Charfeddine and PérezCabal (2017) reported mild cases to represent 94, 87, and $85 \%$ of digital dermatitis, sole ulcer, and white line disease cases, respectively. The weighted means and corresponding standard deviations, calculated as a $10 \%$ coefficient of variation from the mean, were used in normal distributions to create stochastic disorderspecific on-farm labor cost estimates (Table A1). All values drawn from these distributions were truncated at a minimum of 0 , meaning if a value less than 0 was drawn from the distribution, the distribution was resampled assuming there would never be decreased costs associated with on-farm labor resulting from a foot disorder case. The cost associated with on-farm labor was assumed identical regardless of parity group and incidence timing.

Data from the survey conducted in Dolecheck et al. (2018) were also used to define discarded milk per case, as required after treatment with antibiotics. We assumed that only digital dermatitis would result in 
discarded milk because antibiotic use was rarely reported for both sole ulcers and white line disease cases. Survey respondents were asked to indicate the number of days required for milk discard (on average) for a case of digital dermatitis $(\mathrm{n}=22$ responses). The digital dermatitis days to discard milk data were fit to a single stochastic distribution using the distribution fitting feature in @Risk (Table A1). The fitted distribution for days to discard milk following a case of digital dermatitis was an exponential distribution. That stochastic distribution was chosen to represent severe digital dermatitis cases; an assumption was made that mild digital dermatitis cases would not require antibiotic treatment and, therefore, would require no milk discard. To calculate the days to discard milk for a case of digital dermatitis, regardless of severity, the stochastic output for days to discard milk for severe cases and the assumed days to discard milk for mild cases (0) were weighted by severity incidence, as found in Charfeddine and Pérez-Cabal (2017). To account for differences in milk production, discarded milk losses associated with digital dermatitis were made both parity group- and incidence timing-specific. This was accomplished by multiplying the stochastic number of days of milk discard by the average milk production per day for a cow with digital dermatitis in the appropriate parity group (primiparous or multiparous) and time period (0 to 60,61 to 120,121 to 240 , and $>240$ DIM). Lastly, the resulting weight of milk lost per case was multiplied by the stochastic milk price to calculate the value of discarded milk associated with each lameness event. We assumed discarded milk was not fed to calves; if discarded milk were fed to calves, losses associated with discarded milk would be reduced, therefore reducing the cost per case of digital dermatitis.

Milk Loss Module. The milk loss module calculated the losses associated with the reduced production potential of cows experiencing foot disorders. Milk losses were disorder type-, parity group-, and incidence timing-specific. Charfeddine and Pérez-Cabal (2017) reported the mean and standard error ECM loss $(\mathrm{kg} / \mathrm{d})$ associated with a case of mild and severe digital dermatitis, sole ulcer, and white line disease for 4 wk before and after disorder occurrence in primiparous and multiparous cows separately. Those reported values were weighted by the severity incidence reported in Charfeddine and Pérez-Cabal (2017) to calculate a single milk loss value for each disorder, regardless of severity.

The mean and standard error ECM loss $(\mathrm{kg} / \mathrm{d})$ for each disorder, parity, and week relative to disorder incidence combination were used to calculate the expected 2.5th and 97.5th percentiles, which were used in program evaluation and review technique (PERT) distributions to create stochastic estimates for milk loss associated with each foot disorder combination for each of the $4 \mathrm{wk}$ before and after occurrence (Table A2). If the distribution parameters were positive, they were adjusted to zero, as we assumed this was because higher-producing cows were more susceptible to disease rather than the disorder actually increasing milk production (Bewley et al., 2010). The PERT distribution is a type of $\beta$ distribution adjusted for skewness by defining the minimum, mean, and maximum values or, alternatively, percentiles (Bewley et al., 2010). For all disorder cases, an assumption was made that all weeks postdisorder incidence $\geq 4$ were identical. This meant that milk production potential was reduced for the remainder of the lactation after lameness incidence, making losses associated with reduced milk production incidence timing-specific. Similar assumptions about milk loss continuing throughout lactation were also made in previous lameness cost estimate models (Cha et al., 2010; Liang et al., 2017). Altogether, the total milk loss per case of foot disorder was the sum of milk loss for every week from 4 wk before disorder occurrence until the end of the lactation.

Milk loss per case for each incidence timing ( 0 to 60 , 61 to 120,121 to 240 , and $>240$ DIM) was calculated by summing the milk loss associated with a case occurring every day within that incidence timing period and taking the average. Milk loss per case was multiplied by the stochastic milk price to calculate reduced milk revenues. The feed costs associated with producing that milk were subtracted from the total reduced milk revenue losses to account for the fact that the cow responds to reduced milk production by eating less. Reduced feed costs were calculated by multiplying the estimated reduction in DMI (calculated as the average cow's daily intake over the lactation divided by the average cow's daily production over the lactation multiplied by the amount of milk lost) by the stochastic feed price.

Days Open Module. The days open module calculated the losses associated with extended days open resulting from cows experiencing foot disorders. Extended days open losses were disorder type-, parity group-, and incidence timing-specific. Charfeddine and Pérez-Cabal (2017) reported the mean and standard error increase in days open associated with mild and severe digital dermatitis, sole ulcer, and white line disease for primiparous and multiparous cows combined. Those reported values were weighted by the severity incidence reported in Charfeddine and Pérez-Cabal (2017) to calculate a single extended days open value for each disorder, regardless of severity.

The mean and standard error increase in days open for each foot disorder was used to calculate the expected 2.5th and 97.5th percentiles, which were used in PERT distributions to create stochastic estimates 
for the number of extended days open associated with each foot disorder (Table A3). For each distribution, if the mean or 2.5 th percentile were negative (indicating a decrease in days open) they were adjusted to zero, assuming no positive effect of disease on days open.

The losses associated with extended days open were calculated separately for parities 1, 2, and 3 using RPO values. For each parity, the RPO of an average cow in the herd on the first day of that parity was compared with the RPO of a disorder-infected cow on the first day of that parity. The only difference between the 2 cows was the difference in days open during that parity, so the difference in RPO represented the total loss in the cow's value associated with extended days open for that case. For example, if the RPO of the average cow without any disorder on d 1 of lactation 1 was $\$ 825$ and the RPO of the average cow with a sole ulcer $(+3.3 \mathrm{~d}$ open) on d 1 of lactation 1 was $\$ 820$, then the total losses associated with extended days open for a parity 1 cow experiencing a sole ulcer were $\$ 5$. This method has previously been described by Dolecheck et al. (2016) and was applied in the model by Liang et al. (2017).

The multiparous parity group extended days open cost per case was a weighted average of the calculated cost of extended days open per case for cows in parity 2 and 3 , based on the assumed distribution of cows among parities (Table 1). To calculate costs by incidence timing, an assumption was made that disorder cases occurring before the average cow became pregnant resulted in all losses associated with extended days open and disorder cases occurring after the average cow became pregnant resulted in no losses associated with extended days open. For incidence timings that contained the average cow's DIM at conception, a portion of the losses associated with extended days open were included to account for some cases occurring before the average cow becomes pregnant and some cases occurring after the average cow becomes pregnant. For example, if the average cow's days open was $150 \mathrm{~d}$ and the days open losses per case were $\$ 20$, then the losses per case associated with extended days open for the incidence timing 121 to 240 DIM were $\$ 5$ [ $\$ 20 \times$ $(150-121) /(240-121)]$. The DIM at conception for the average cow was calculated using the equation by Pecsok et al. (1994) with the voluntary waiting period and DIM do not breed set deterministically at 60 and 250 DIM, respectively, and pregnancy rate calculated using stochastic distributions for estrus detection rate and conception rate defined by data from DairyMetrics (Dairy Records Management Systems, Raleigh, NC; Table 1 and Table 2).

Culling and Death Module. The culling and death module calculated the losses associated with an increased risk of culling and death resulting from foot disorders. The losses associated with an increased risk of culling and death were disorder type-, parity group-, and incidence timing-specific. Mean, 5th percentile, and 95th percentile culling hazard ratios associated with digital dermatitis and sole ulcers were reported by Booth et al. (2004), specifically considering how the incidence of disease in one period ( 0 to 60,61 to 150, 151 to 240 , or $>240$ DIM) influenced culling in both that time period and future time periods. These values were used to create stochastic distributions for disorder-specific culling hazard ratios, assuming white line disease culling hazard ratios were identical to sole ulcers (Table A4). The assumption about similarities between sole ulcer and white line disease were made because they are both noninfectious foot disorders and Charfeddine and Pérez-Cabal (2017) reported similar effects of both disorders on the length of productive life. All distributions were truncated at a minimum of 1.0, meaning if a value less than 1.0 was drawn from the distribution (indicating a decreased risk of culling) the distribution was resampled assuming no positive effect of disease on culling.

The culling hazard ratios were used to calculate the number of extra culls resulting from each foot disorder case, as previously described by Bewley et al. (2010). To calculate losses associated with the extra culls, the RPO value of the average cow for each combination of parity $(1,2,3,4,5$, and 6$)$ and incidence timing was multiplied by the number of extra culls per case in that parity and incidence timing. Culling losses per case were calculated separately for parities $1,2,3,4$, 5 , and 6 . The weighted average of parities $\geq 2$, based on the distribution of cows among parities (Table 1), was used to represent culling losses associated with the multiparous parity group.

No previous research has estimated the percentage of specific foot disorder cases resulting in death. An assumption was made in this model that losses associated with an increased risk of death for all digital dermatitis cases was $\$ 0$, indicating very little chance of death following diagnosis with digital dermatitis. For sole ulcer and white line disease cases an assumption was made that $1 \%$ of cases occurring at any incidence timing would result in death (natural or euthanized). Disorder-related death losses were calculated for each incidence timing and parity $(1,2,3,4,5$, or 6$)$ by multiplying the number of deaths per case for each incidence timing and parity by the mean slaughter value (calculated as the BW of the average cow multiplied by the stochastic slaughter price) for that specific time period in that specific lactation. Death losses per case for multiparous cows were the weighted average of each parity $\geq 2$, based on the assumed distribution of cows among parities (Table 1). 
Table 1. Deterministic farm performance and financial inputs used in a stochastic model to estimate the cost of 3 different dairy cow foot disorders

\begin{tabular}{|c|c|c|}
\hline Input & Value & Source $^{1}$ \\
\hline \multicolumn{3}{|l|}{ Farm performance inputs } \\
\hline Baseline culling rate (\%) & 13.0 & Bewley et al. (2010) \\
\hline Butterfat yield (\%) & 3.7 & DairyMetrics \\
\hline Protein yield $(\%)$ & 3.1 & DairyMetrics \\
\hline Calf birth weight (kg) & 41.7 & Kertz et al. (1997) \\
\hline Mature cow live weight $(\mathrm{kg})$ & 723 & NRC $(2001)$ \\
\hline Age at first calving (mo) & 24.3 & DairyMetrics \\
\hline Voluntary waiting period (d) & 59.3 & DairyMetrics \\
\hline DIM designated do not breed & 250 & Authors' expertise \\
\hline Gestation length $(\mathrm{d})$ & 280 & Norman et al. (2009) \\
\hline Days dry & 56.2 & NAHMS (2014) \\
\hline Close up dry period length (d) & 21 & Authors' expertise \\
\hline Percent heifer calves & 46.7 & Silva del Río et al. (2007) \\
\hline Percent of herd in 1st parity & 36.1 & Dhuyvetter et al. (2007) \\
\hline Percent of herd in 2 nd parity & 26.0 & Dhuyvetter et al. (2007) \\
\hline Percent of herd in 3rd parity & 17.7 & Dhuyvetter et al. (2007) \\
\hline Percent of herd in 4 th parity & 11.0 & Dhuyvetter et al. (2007) \\
\hline Percent of herd in 5th parity & 5.8 & Dhuyvetter et al. (2007) \\
\hline Percent of herd in 6 th (or greater) parity & 3.4 & Dhuyvetter et al. (2007) \\
\hline \multicolumn{3}{|l|}{ Financial inputs } \\
\hline Discount rate $(\%)$ & 8.0 & Authors' expertise \\
\hline Far off dry cow feed price $(\$ / \mathrm{kg}$ of $\mathrm{DM})$ & 0.15 & Authors' expertise \\
\hline Close up dry cow feed price $(\$ / \mathrm{kg}$ of DM $)$ & 0.22 & Authors' expertise \\
\hline Bull calf price $(\$)$ & 81.31 & Gould and Bozic (2018) \\
\hline Heifer calf price $(\$)$ & 63.47 & Gould and Bozic (2018) \\
\hline Breeding costs (\$/insemination) & $15.51^{2}$ & VanRaden and Cole (2014) \\
\hline Disposal losses $(\$)$ & $65^{2}$ & Groenendaal et al. (2004) \\
\hline
\end{tabular}

Disease Recurrence Module. The disease recurrence module calculated losses linked to cases recurring in the same animal. Disease recurrence losses were disorder type-, parity group-, and incidence timingspecific. Charfeddine and Pérez-Cabal (2017) reported mean relapse rates (episodes per infected cow) for both primiparous and multiparous cows experiencing either mild or severe digital dermatitis, sole ulcers, and white line disease. Those values were weighted by the incidence of severity reported by Charfeddine and PérezCabal (2017) to calculate relapse rates for each disorder, regardless of severity. Each of these assumptions was modeled stochastically using a PERT distribution (Table A5), with minimum and maximum values assumed identical for all foot disorders using the general lameness relapse rate values reported by Ettema and

Table 2. Simulated farm performance and market price inputs used in a stochastic model to estimate the cost of 3 different dairy cow foot disorders

\begin{tabular}{lccc}
\hline Input & $\begin{array}{c}\text { Simulated range } \\
\text { (minimum-maximum })\end{array}$ & $\begin{array}{c}\text { Simulated } \\
\text { mean } \pm \text { SD }\end{array}$ & Source $^{1}$ \\
\hline Farm performance inputs & & & DairyMetrics \\
$\quad$ Rolling herd average milk production $(\mathrm{kg})$ & $4,899-18,113$ & $11,458 \pm 2,003$ & DairyMetrics \\
Conception rate $(\%)$ & $10-88$ & $56.5 \pm 14.5$ & DairyMetrics \\
Estrus detection rate $(\%)$ & $10-100$ & $22.4 \pm 11.2$ & DairyMetrics \\
Pregnancy rate $(\%)$ & $2.1-66.3$ & $0.29 \pm 0.05$ & FAPRI (2018) \\
Market price inputs & $0.22-0.39$ & $0.36 \pm 0.06$ & FAPRI (2018) \\
Lactating feed price $(\$ / \mathrm{kg}$ of $\mathrm{DM})$ & $0.28-0.47$ & $1,629 \pm 143$ & Gould and Bozic $(2018)$ \\
Milk price $(\$ / \mathrm{kg})$ & $1,433-1,885$ & $1.45 \pm 0.22$ & FAPRI (2018) \\
Replacement heifer price $(\$)$ & $1.08-1.89$ & & \\
Slaughter value $(\$ / \mathrm{kg})$ & &
\end{tabular}

${ }^{1}$ DairyMetrics information was collected on October 1, 2017, from Dairy Records Management Systems (Raleigh, NC). Values gathered from DairyMetrics included 1,987 United States Holstein herds with at least 200 cows. 
Østergaard $(2006 ;$ minimum $=1.5$, maximum $=4.0)$. The stochastic relapse rate minus 1 was the number of repeat cases expected per original case. However, incidence timing and disorder length logically influence how many repeat cases per original case can occur within the same lactation. Therefore, disorder length estimates were incorporated into the model.

Bruijnis et al. (2010) reported mean, 5th percentile, and 95th percentile disorder length for subclinical and clinical digital dermatitis, sole ulcer, and white line disease. Those values were weighted by the incidence of severity reported by Charfeddine and Pérez-Cabal (2017) to calculate relapse rates for each disorder, regardless of severity, and were then used in PERT distributions to create stochastic estimates of disorder length for each foot disorder (Table A5). By multiplying the disorder length by the relapse rate, the length of time (d) required for all cases (original plus relapse cases) to occur was calculated.

To make losses associated with disease recurrence incidence timing-specific, a comparison was made between the length of time required for all cases (original and relapse) to occur and the number of days remaining in the lactation. We assumed that a new case occurring within each incidence timing occurred at the midpoint of that period (e.g., for incidence timing 0 to 60 DIM, incidence occurred at 30 DIM). The remaining days left in the lactation were calculated by subtracting the incidence timing from the average cow's length of lactation, as determined by the calving interval. For example, if the average cow's length of lactation was $375 \mathrm{~d}$, then $345 \mathrm{~d}$ would be left in the lactation for incidence timing at 0 to 60 DIM (375 minus 30). By comparing this to the time required for all lameness cases (original and relapse) to occur, we could calculate the number of actual recurrences that would happen within a lactation. Using this method, more recurring cases were assumed for a case of lameness occurring in early lactation than a case occurring in later lactation, simply because the days remaining in the lactation would not permit the case to recur at the same rate. We assumed no adverse effects of foot disorders occurring in late lactation on the subsequent lactation because of a lack of published data on this relationship.

For recurring cases, we assumed costs associated with treatment, labor, and discarded milk reoccurred at $100 \%$ of the price of the first episode, whereas no extra losses were associated with reduced milk production, extended days open, an increased risk of culling, or an increased risk of death. This assumption was likely conservative, but was necessary considering the lack of data available to show how recurring cases influence a cow's milk yield, reproductive performance, risk of culling, and risk of death.

\section{Model Demonstration}

The estimated individual expenditures and losses from the treatment, milk loss, days open, culling and death, and disease recurrence modules were combined to calculate the total cost per case of each foot disorder. To demonstrate model usefulness, 1,000 iterations of the model were run using Latin Hypercube sampling. The mean \pm standard deviation cost per case of foot disorder across all disorder type, parity group, and incidence timing combinations was reported. Default deterministic variable assumptions used to define the herd and the average cow were collected from Dairy Records Management Systems (Raleigh, NC) using limitations of only Holstein herds with $\geq 200$ cows, published literature, or our own expertise (Table 1). The resulting distributions of herd-level stochastic variables can be found in Table 2. Inputs used in the model for our study were meant to represent a US dairy herd; however, model inputs could be adjusted to herd-specific values to calculate the estimated cost of foot disorders for a specific herd.

\section{Sensitivity Analysis}

As described for each module, many variables were stochastic within the model, including labor costs, therapeutic costs, days of discarded milk, expected milk loss, extended days open, culling hazard ratios, disorder recurrence rates, and disorder length. However, only selected market prices and herd-specific performance variables were included in a sensitivity analysis to test how they affected the disorder costs, because these variables are either more controllable by or more readily available to the producer. The selected variables included milk price, feed price, replacement heifer price, slaughter price, and pregnancy rate (calculated as the multiplication of estrus detection rate and conception rate). Using the @Risk sensitivity analysis function, a multivariate regression analysis was conducted between these stochastic variables and the mean total cost per case of each foot disorder across all combinations of parity group and incidence timing. The results of this analysis show how the cost per disorder case changes with a 1 standard deviation increase in each stochastic factor.

\section{RESULTS AND DISCUSSION}

The objective of our study was to build a stochastic simulation model capable of estimating the cost per case of a foot disorder depending on disorder type, parity group, and incidence timing. This was accomplished by incorporating modules to account for outside (hoof 
trimmer) labor, therapeutics, on-farm labor, discarded milk, reduced milk production, extended days open, an increased risk of culling, an increased risk of death (natural or euthanized), and disease recurrence into a pre-existing stochastic simulation model.

Model accuracy may be limited by the fact that few previous studies have considered foot disorder expenditure and loss estimates specific to disorder type, parity group, and incidence timing. Because of this, a single study (Charfeddine and Pérez-Cabal, 2017) was used to estimate the majority of losses associated with the different foot disorders. That study was conducted in Spain, whereas our model was focused on calculating foot disorder costs in US dairy herds. Although some differences between Spanish and American dairies likely exist, the values used from that study were expected physiological responses (i.e., reduced milk yield, extended days open, and so on) rather than direct economic values, which are likely less different between countries. However, further research considering expected physiological responses to foot disorders in United States dairy herds would be valuable, and disorder cost estimates should be recalculated following the completion of such studies.

Some assumptions used in our estimates may have resulted in an underestimation of foot disorder costs. For example, Charfeddine and Pérez-Cabal (2017) did not account for culling bias (i.e., culled cows were not included in all milk loss calculations) or the increased likelihood that a higher-producing cow would get a foot disorder; therefore, the estimates for reduced milk production are likely biased low. Culling bias also affected estimates used in the model for extended days open because only those cows that became pregnant were considered within their analysis (i.e., the impact of cows who did not become pregnant was not included). Additionally important to note is that the model assumed a replacement heifer was always available to replace a cow that was either culled or died. However, if replacements were limited, the cost per case of lameness would increase as the cost of replacements would increase. The potential underestimation of disease recurrence costs may have also contributed to an underestimated total cost per case of foot disorder estimates in our study.

Additionally, little data exists on the effects of foot disorders beyond the current lactation. Therefore, our foot disorder cost estimates only included expenditures and losses within the same lactation as disorder occurrence. Further research is need to better define the effects of lameness in one lactation on production and reproduction losses in the next lactation. Our disorder cost estimates also do not account for the severity of the disorder. One would expect a more severe case to result in larger negative effects (i.e., reduced milk produc- tion, extended days open), resulting in increased costs compared with a mild case. Given that only 1 study was identified that considered how severity affected the physiological response of the cow, we chose not to specify severity in our estimates so as not to produce bad estimates. More research on the differences in cow production responses based on severity of the disorder would make this possible to include in our model.

Finally, using a spreadsheet approach to calculate disorder costs limited the ability to build additional complexity into the model. For example, further application of the RPO module to calculate other disorder related costs beyond extended days open and the increased risk of culling, such as milk losses, could provide more accurate disorder cost estimates. Future modeling efforts should consider alternative modeling approaches, such as dynamic programming. Ultimately, the disorder cost estimates from our model demonstration should be interpreted carefully while keeping these limitations in mind.

\section{Disorder Cost Estimates}

Digital Dermatitis. The simulated mean \pm standard deviation cost per case of digital dermatitis by parity group and incidence timing is presented in Table 3 ; patterns among results are presented in Figure 1. Over all combinations, the mean \pm standard deviation cost per case of digital dermatitis was $\$ 64 \pm 24$, ranging from a low of $\$ 34 \pm 21$ in a postpeak lactation (121 to 240 DIM), primiparous cow to a high of $\$ 122 \pm 45$ in an early lactation, multiparous cow.

Some previous estimates of the cost of digital dermatitis have been larger than the mean found in this study (\$145 and $\$ 153 /$ case after adjustment to 2018 dollars; Willshire and Bell, 2009; Cha et al., 2010). Reduced estimates in the current study could be related to the conservative values used to estimate losses associated with reduced milk production, extended days open, and disease recurrence. Charfeddine and Pérez-Cabal (2017) estimated a mild and severe case of digital dermatitis to be $\$ 54$ and $\$ 413$ (adjusted to 2018 dollars), respectively. If those estimates were weighted by the proportion of mild and severe cases found in their study (94\% mild and $6 \%$ severe), then the mean cost per case $(\$ 76)$ would be similar to the value found in our study. We noted 3 main differences in how our cost estimates were calculated as compared with Charfeddine and Pérez-Cabal (2017). First, the estimates for therapeutics and outside labor assumed in our study [from Dolecheck et al. (2018)] were less than those found by Charfeddine and Pérez-Cabal (2017), likely because of differences in study location (United States vs. Spain) and the increased likelihood of veterinary involvement 
FOOT DISORDER COST ESTIMATES

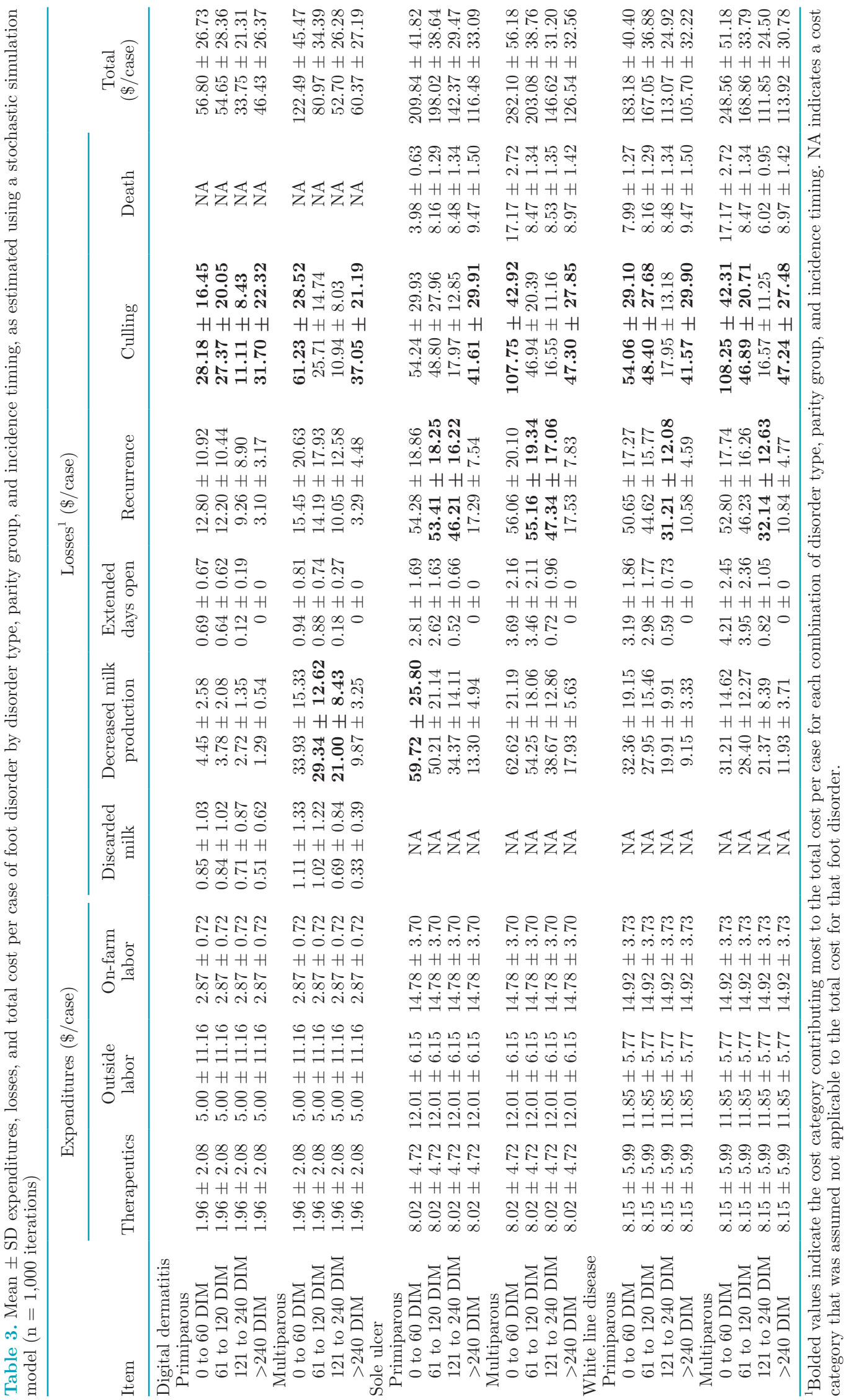


in Spain as compared with the United States. Second, discarded milk was assumed to be minimal in our study compared with Charfeddine and Pérez-Cabal (2017), who reported that antibiotic use was standard for all severe lesions. Third, our study assumed that the cost of a recurring case only included direct costs (therapeutics, outside labor, on-farm labor, and discarded milk) because minimal evidence exists to differentiate milk loss, extended days open, risk of culling, and risk of death associated with the first versus second case of a foot disorder. Comparatively, Charfeddine and PérezCabal (2017) assumed recurring cases to have the same cost as the first case.

As shown in Figure 1, cases in primiparous cows were less expensive than comparable cases (identical incidence timing) in multiparous cows. Over all foot disorder cost estimates, cases occurring in multiparous cows were either similar or more expensive than cases occurring in primiparous cows. Although primiparous cows generally have a greater future value (as calculated by the RPO), this was offset by the greater production levels (and therefore greater milk loss) of multiparous cows given the market conditions assumed in our example. Similar results comparing disease costs in primiparous and multiparous cows were found by Liang et al. (2017). Compared with multiparous cows, primiparous cows experienced fewer losses associated with decreased milk production, extended days open, an increased risk of culling, and disease recurrence (Table 3). Across incidence timing, mean case costs generally decreased over the lactation of the cow, with a small increase late in lactation (Figure 1). All variable cost categories decreased as DIM at incidence increased except for culling losses. Losses associated with culling were bimodal, peaking in both early and late lactation. Our assumptions about the effects of foot disorders on culling were taken from Booth et al. (2004), who found that the $95 \%$ confidence interval for the risk of culling when foot disorders occurred in later lactation was wider than the $95 \%$ confidence interval for the risk of culling when foot disorders occurred in earlier lactation. This resulted in our model estimating an increased risk of culling for cases occurring in later lactation, which may be overestimated. More research is needed to accurately estimate the effects of foot disorder timing on culling.

In primiparous cows, losses associated with an increased risk of culling always represented the greatest contribution to the total cost per case, regardless of incidence timing (mean $=50 \%$ of the total cost). In multiparous cows, losses associated with an increased risk of culling represented the greatest contribution to the total cost per case in early or late lactation (mean $=56 \%$ of the total cost), whereas losses associated with decreased milk production represented the greatest contribution when incidence occurred between 61 and

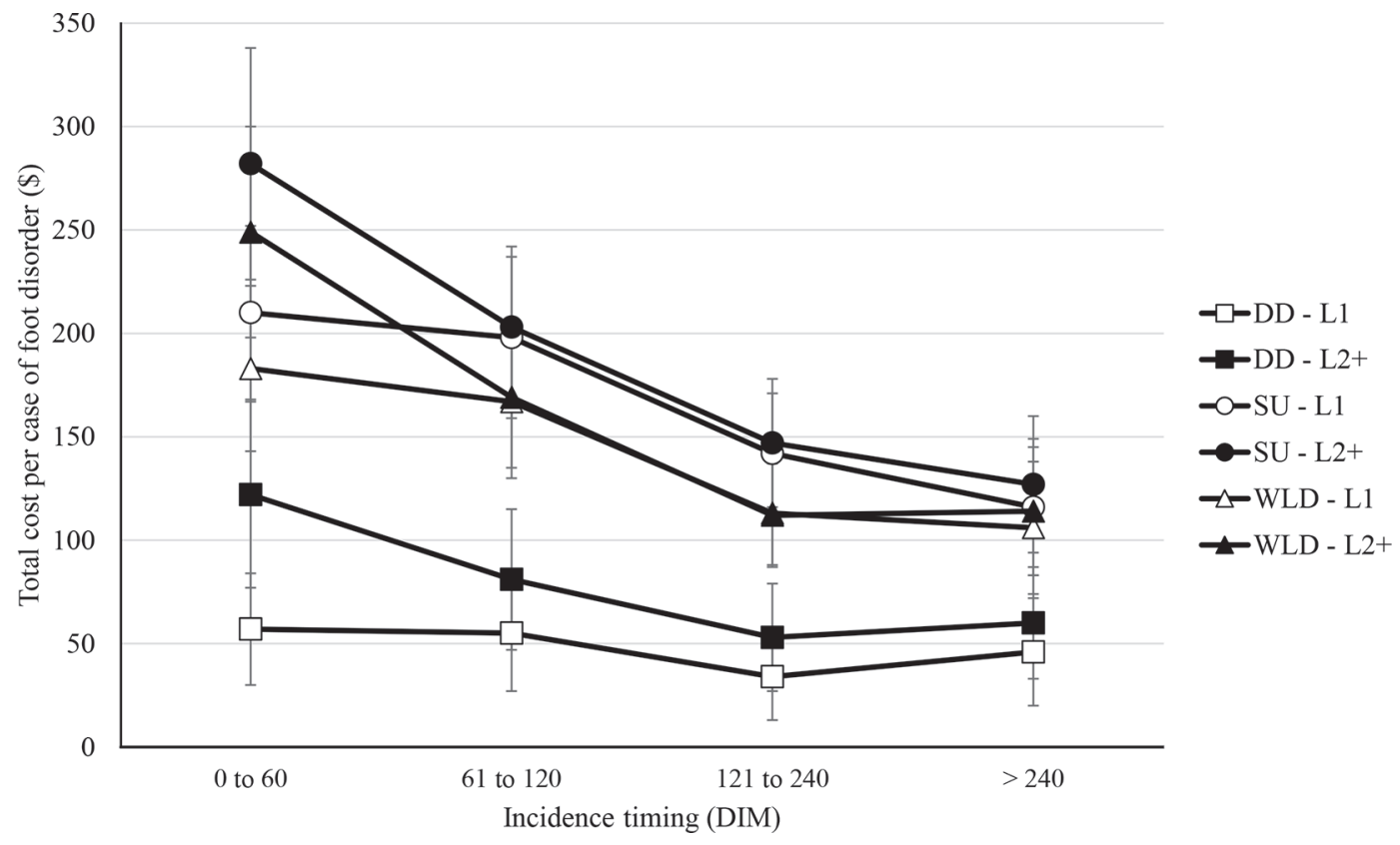

Figure 1. Variation (mean $\pm \mathrm{SD}$ ) in the total cost per case of foot disorder by disorder type (DD = digital dermatitis; $\mathrm{SU}=$ sole ulcer; WLD $=$ white line disease), parity group (L1 = primiparous; L2 $+=$ multiparous), and incidence timing as estimated using a stochastic simulation model ( $\mathrm{n}=1,000$ iterations). 
240 DIM (mean $=38 \%$ of the total cost). The remaining contributions of each cost category varied by parity group and incidence timing (Table 3 ). Charfeddine and Pérez-Cabal (2017) found that expenditures on outside labor and losses associated with reduced milk production contributed the most to the cost per affected cow in mild digital dermatitis cases (43 and 34\%, respectively), whereas losses associated with an increased risk of death and culling and discarded milk contributed the most to the cost per affected cow in severe digital dermatitis cases (37 and 24\%, respectively). However, recurrence losses were not considered as their own category by Charfeddine and Pérez-Cabal (2017), making direct comparisons difficult.

It is worth noting that none of the current cost estimates for digital dermatitis, including those in our study, included the cost of transmission. Digital dermatitis is a contagious disease, and ignoring the costs of additional cases of digital dermatitis resulting from one original case ignores the full economic losses of the disorder. Döpfer et al. (2012) estimated the reproductive ratio of digital dermatitis to be between 0.5 and 3.3, depending on the prevention strategy used. Therefore, this cost category could make up a large portion of the cost per case of digital dermatitis, depending on herd-level prevention strategies in place. Modeling of contagious diseases is complex, which is why this cost category is typically not included in digital dermatitis case cost estimates.

Sole Ulcer. The simulated mean \pm standard deviation cost per case of a sole ulcer by parity group and incidence timing is presented in Table 3; patterns among results are presented in Figure 1. Over all combinations, the mean \pm standard deviation cost per case of sole ulcers was $\$ 178 \pm 29$, ranging from a low of $\$ 116 \pm 33$ in a late lactation, primiparous cow to a high of $\$ 282 \pm 56$ in an early lactation, multiparous cow. Our reported mean was lower than the sole ulcer cost estimates of $\$ 248$ and $\$ 992$ (adjusted to 2018 dollars) reported by Cha et al. (2010) and Willshire and Bell (2009), respectively. Charfeddine and Pérez-Cabal (2017) estimated the cost per case of a mild and severe sole ulcer to be $\$ 238$ and $\$ 638$, respectively (adjusted to 2018 dollars). The lower cost estimates found in our study may be for similar reasons as the differences found for digital dermatitis.

Unlike digital dermatitis, parity group appeared to minimally affect the cost per case of sole ulcer (Figure 1). In fact, cases occurring at any incidence timing except early lactation were within $\$ 11$ of each other (Table 3). Across incidence timing, case costs in both parity groups decreased over the lactation of the cow (Figure 1). Compared with digital dermatitis, sole ulcers were associated with more extreme effects on reduced milk yield, extended days open, and an increased risk of culling or death, which were all influenced by stage of lactation. Similar to digital dermatitis, all variable cost categories decreased further in lactation except for those associated with an increased risk of culling or death. The peak in losses associated with an increased risk of death differed by parity group, but tended to follow the slaughter value of the cow, which was highest at the beginning and end of lactation, following $\mathrm{BW}$ patterns.

Across all sole ulcer cases, the losses associated with reduced milk production, disease recurrence, and an increased risk of culling made up most of the total cost per case (mean $=22,24$, and $26 \%$ of the total cost, respectively). The remaining contributions of each cost category varied by parity group and incidence timing (Table 3). Similarly, Kossaibati and Esslemont (1997) and Esslemont (2005) estimated that the combined costs of culling and death contributed most to the total cost of sole ulcers (33 to 36\%); however, they estimated reduced reproductive performance to contribute the second most to total sole ulcer costs (30 to $32 \%$ ). Losses associated with extended days open in our study were based on the assumption that sole ulcers resulted in 3.3 \pm 1.6 extended days open, whereas both Kossaibati and Esslemont (1997) and Esslemont (2005) assumed sole ulcers resulted in 40 extended days open, which partially explains our difference in findings. Additionally, our method of calculating the cost per day open tends to be more conservative than other estimates (Dolecheck et al., 2016). Charfeddine and Pérez-Cabal (2017) estimated that the losses associated with an increased risk of culling contributed most (40 and $23 \%$ for mild and severe cases, respectively) to the total cost of a sole ulcer, followed by discarded milk ( $20 \%$ in severe cases) and reduced milk yield (18 and 16\% for mild and severe cases, respectively).

White Line Disease. The simulated mean \pm standard deviation cost per case of white line disease by parity group and incidence timing is presented in Table 3 ; patterns among results are presented in Figure 1. Over all combinations, the mean \pm standard deviation cost per case of white line disease was $\$ 152 \pm 26$, ranging from a low of $\$ 106 \pm 32$ in a late lactation, primiparous cow to a high of $\$ 249 \pm 51$ in an early lactation, multiparous cow. Willshire and Bell (2009) estimated costs associated with white line disease to be greater ( $\$ 574 /$ case after adjustment to 2018 dollars), but assumed 30 extended days open resulting from the disorder, whereas our assumed mean extended days open for a case of white line disease was $3.7 \pm 1.7 \mathrm{~d}$. Charfeddine and Pérez-Cabal (2017) estimated a mild case of white line disease to cost $\$ 227$ and a severe case to cost $\$ 605$, assuming greater therapeutic and supply 


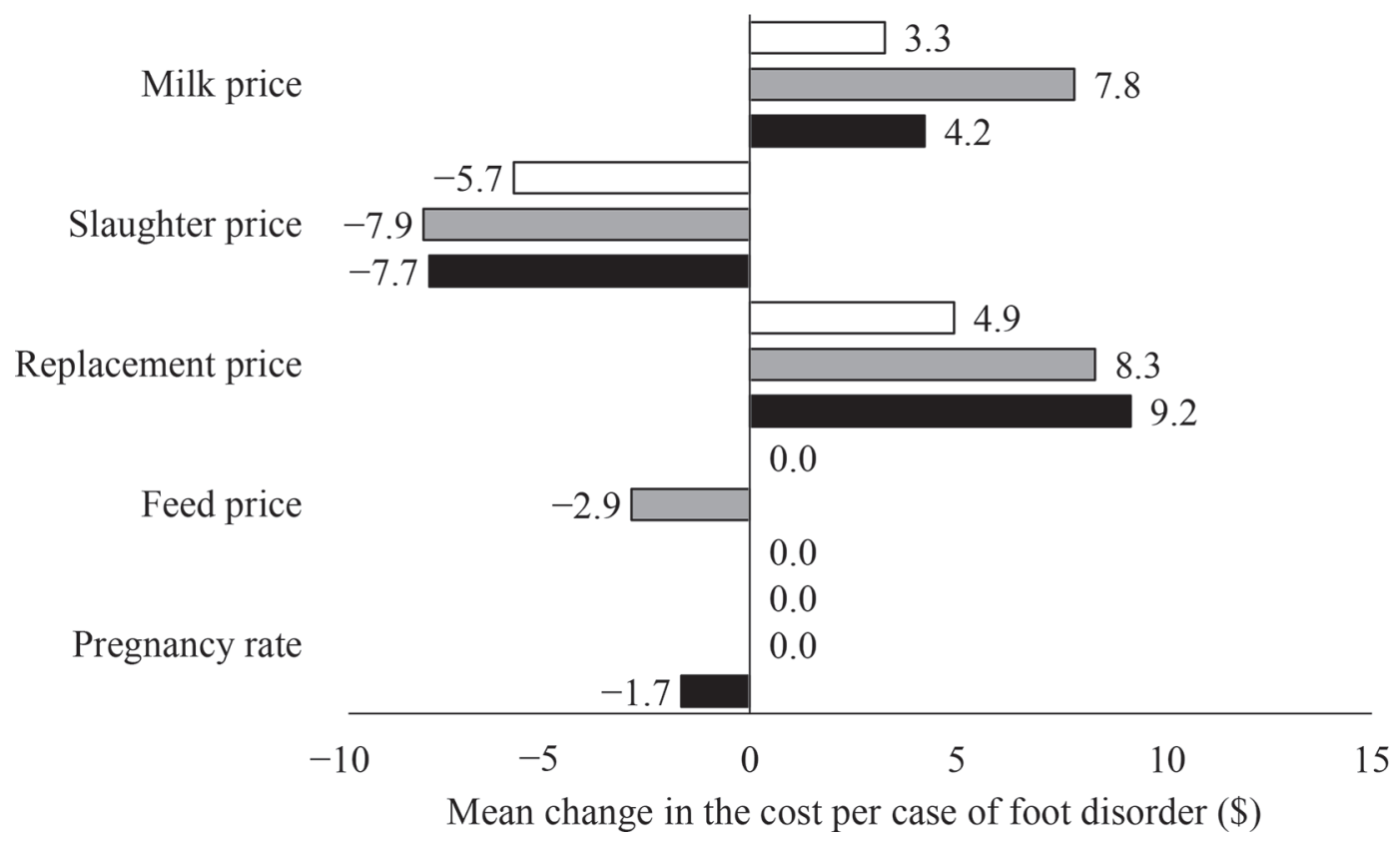

Figure 2. Tornado graph indicating the change $(\$)$ in digital dermatitis (white bars), sole ulcer (gray bars), and white line disease (black bars) total cost per case with a $1 \mathrm{SD}$ increase in selected stochastic market prices and herd-specific performance variables as estimated using a stochastic simulation model ( $\mathrm{n}=1,000$ iterations).

costs as well as the possibility of discarded milk losses, which were not included in our study.

Similar to sole ulcers, parity group appeared to minimally affect the cost per case of white line disease. Across incidence timing, case costs generally decreased over the lactation of the cow (Figure 1). Regardless of parity, the cost category that contributed the most to the total cost per case for all incidence timings except the postpeak period (121 to 240 DIM) was losses associated with an increased risk of culling (mean $=35 \%$ of the total cost). During the postpeak period, losses associated with disease recurrence contributed the most to the total cost $($ mean $=28 \%$ of the total cost $)$. The remaining contributions of each cost category varied by parity group and incidence timing (Table 3). Only Charfeddine and Pérez-Cabal (2017) have previously broken down cost categories for white line disease, with very similar estimates to sole ulcers (30 to $39 \%$ increased risk of culling or death, 13 to $17 \%$ reduced milk production, and $20 \%$ discarded milk in severe cases).

\section{Sensitivity Analysis}

The change in the total cost per case of each disorder (across all parity group and incidence timing combinations) as selected market prices and herd-specific performance variables increased by 1 standard deviation is displayed in Figure 2. Across all disorders, the cost per foot disorder case increased in response to a 1 standard deviation increase in milk price or replacement heifer price. As milk price increased the cost per case increased because there was more potential income from milk production being lost through both discarded milk and reduced milk yield. Milk price influenced the cost per case more in higher-milk production potential situations, such as multiparous cows with earlier incidence timing (because milk loss would continue throughout lactation). As replacement heifer price increased, the cost to replace an animal that was culled or died increased, thereby increasing the cost per disorder.

Across all disorders, the cost per foot disorder case decreased or remained similar in response to a 1 standard deviation increase in feed price, pregnancy rate, or slaughter price. In response to foot disorder incidence and the resulting lower milk production, cows were assumed to eat less; therefore, a cow with a foot disorder would have lower feed costs and the cost per disorder would be lowered when feed costs are high. Feed price influenced the cost per case of sole ulcer most because sole ulcers were associated with the greatest milk loss, especially in late lactation, multiparous cows. As pregnancy rate increased, the adverse effects of a foot disorder on reproduction became less detrimental, therefore lowering the cost per foot disorder. In other words, if a herd was already getting cows pregnant quickly, adding a few more days open would be less detrimental than in a herd that was already struggling to get cows pregnant. Finally, as slaughter price increased, the cost 
of culling a cow decreased, therefore lowering the cost per foot disorder.

The 3 most important of the selected market prices and herd-specific performance variables appeared to be the milk price, replacement heifer price, and slaughter price. Increasing the slaughter price resulted in the largest change in the cost per case of digital dermatitis (-\$5.7), whereas increasing replacement heifer price resulted in the largest change in the cost per case of either sole ulcer or white line disease ( $\$ 8.3$ and $\$ 9.2$, respectively). Increasing the milk price resulted in the third largest change in the cost per case of all disorders. The reason these 3 market prices had the greatest influence on the cost of foot disorders is likely linked to their heavy involvement in calculating losses associated with reduced milk production and an increased risk of culling; these 2 cost categories were among the largest contributors in all cost per case estimates.

\section{CONCLUSIONS}

The ability to estimate the cost per case of 3 foot disorders (digital dermatitis, sole ulcer, and white line disease) was incorporated into a pre-existing stochastic simulation model. Through this process, missing data in the literature was identified, indicating potential areas for future research. In particular, research considering expenditures and losses specific to individual foot disorders, parity group, disorder timing, and severity level should be considered. Using assumptions meant to represent a US dairy herd, disorder cost estimates calculated using the model varied by not only disorder type, but also parity group and incidence timing. These differences indicated that the cost per case of foot disorder differed by cow. Foot disorder costs were also influenced by market prices and herd-specific performance variables, indicating that foot disorder costs should be considered at the individual herd level. This knowledge could help guide on-farm decisions about foot disorder treatment, culling strategies, and investment in lameness prevention.

\section{ACKNOWLEDGMENTS}

The authors thank Elanco Animal Health (Greenfield, IN), who provided funding to support this research.

\section{REFERENCES}

Bailey, K., and V. Ishler. 2007. Tracking milk prices and feed costs. Department of Agricultural Economics and Rural Sociology. Penn State University Extension, Park City, PA.

Bewley, J., M. Boehlje, A. W. Gray, H. Hogeveen, S. Kenyon, S. Eicher, and M. Schutz. 2010. Stochastic simulation using @Risk for dairy business investment decisions. Agr. Financ. Rev. 70:97-125.
Booth, C. J., L. Warnick, Y. Gröhn, D. Maizon, C. Guard, and D. Janssen. 2004. Effect of lameness on culling in dairy cows. J. Dairy Sci. 87:4115-4122.

Bruijnis, M. R., H. Hogeveen, and E. Stassen. 2010. Assessing economic consequences of foot disorders in dairy cattle using a dynamic stochastic simulation model. J. Dairy Sci. 93:2419-2432.

Cha, E., J. Hertl, D. Bar, and Y. Gröhn. 2010. The cost of different types of lameness in dairy cows calculated by dynamic programming. Prev. Vet. Med. 97:1-8.

Charfeddine, N., and M. A. Pérez-Cabal. 2017. Effect of claw disorders on milk production, fertility, and longevity, and their economic impact in Spanish Holstein cows. J. Dairy Sci. 100:653-665.

Costa, J. H. C., D. M. Weary, and M. A. G. v. Keyserlingk. 2017. Prevalence of lameness and leg injuries on US freestall dairies. J. Dairy Sci. 100(Suppl. 2):26 (Abstr.).

DeFrain, J. M., M. Socha, and D. Tomlinson. 2013. Analysis of foot health records from 17 confinement dairies. J. Dairy Sci. 96:73297339 .

Dhuyvetter, K. C., T. L. Kastens, M. Overton, and J. Smith. 2007. Cow culling decisions: Costs or economic opportunity? Pages 173187 in Proc. of the Western Dairy Management Conference. Reno, NV.

Dolecheck, K., and J. M. Bewley. 2018. Animal board invited review: Dairy cow lameness expenditures, losses, and total cost. Animal $12: 1462-1474$

Dolecheck, K. A., R. M. Dwyer, M. W. Overton, and J. M. Bewley. 2018. A survey of United States dairy hoof care professionals on costs associated with treatment of hoof diseases. J. Dairy Sci. 101:8313-8326.

Dolecheck, K. A., G. Heersche Jr., and J. M. Bewley. 2016. Retention payoff-based cost per day open regression equations: Application in a user-friendly decision support tool for investment analysis of automated estrus detection technologies. J. Dairy Sci. 99:1018210193.

Döpfer, D., M. Holzhauer, and M. van Boven. 2012. The dynamics of digital dermatitis in populations of dairy cattle: Model-based estimates of transition rates and implications for control. Vet. J. 193:648-653.

Esslemont, R. J., and E. Peeler. 1993. The scope for raising margins in dairy herds by improving fertility and health. Br. Vet. J. 149:537-547.

Esslemont, R. J. 2005. The costs of lameness in dairy herds. UK Vet. Livest. 10:41-49.

Ettema, J., S. Østergaard, and A. R. Kristensen. 2010. Modelling the economic impact of three lameness causing diseases using herd and cow level evidence. Prev. Vet. Med. 95:64-73.

Ettema, J. F., and S. Østergaard. 2006. Economic decision making on prevention and control of clinical lameness in Danish dairy herds. Livest. Sci. 102:92-106.

FAPRI. 2018. U.S. Baseline Briefing Book: Projections for Agricultural and Biofuel Markets. Food and Agricultural Policy Research Institute (FAPRI) at the University of Missouri. Accessed Mar. 13, 2018. https://www.fapri.missouri.edu/wp-content/uploads/2018/ 03/2018-Baseline-Outlook-1.pdf.

Gould, B. W., and M. Bozic. 2018. Understanding Dairy Markets. University of Wisconsin-Madison and University of Minnesota. https: //dairymarkets.com/.

Groenendaal, H., D. Galligan, and H. Mulder. 2004. An economic spreadsheet model to determine optimal breeding and replacement decisions for dairy cattle. J. Dairy Sci. 87:2146-2157.

Guard, C. 2008. The costs of common diseases of dairy cattle. Pages 695-700 in Proceedings of the California Veterinary Conference. Advanstar Communications, Lenexa, KS.

Harris, D. J., C. Hibburt, G. Anderson, P. Younis, D. Fitspatrick, A. Dunn, I. Parsons, and N. McBeath. 1988. The incidence, cost and factors associated with foot lameness in dairy cattle in southwestern Victoria. Aust. Vet. J. 65:171-176.

Kaneene, J. B., and H. S. Hurd. 1990. The national animal health monitoring system in Michigan. III. Cost estimates of selected dairy cattle diseases. Prev. Vet. Med. 8:127-140. 
Kertz, A. F., L. Reutzel, B. Barton, and R. Ely. 1997. Body weight, body condition score, and wither height of prepartum Holstein cows and birth weight and sex of calves by parity: A database and summary. J. Dairy Sci. 80:525-529.

Kossaibati, M. A., and R. Esslemont. 1997. The costs of production diseases in dairy herds in England. Vet. J. 154:41-51.

Liang, D., L. M. Arnold, C. J. Stowe, R. J. Harmon, and J. M. Bewley. 2017. Estimating US dairy clinical disease costs with a stochastic simulation model. J. Dairy Sci. 100:1472-1486.

Miller, G. Y., and C. R. Dorn. 1990. Costs of dairy cattle diseases to producers in Ohio. Prev. Vet. Med. 8:171-182.

NAHMS. 2014. Dairy Cattle Management Practices in the United States. USDA-APHIS-VS, ed. National Animal Health Monitoring System, Fort Collins, CO.

Norman, H. D., J. Wright, M. Kuhn, S. Hubbard, J. Cole, and P. M. VanRaden. 2009. Genetic and environmental factors that affect gestation length in dairy cattle. J. Dairy Sci. 92:2259.
NRC. 2001. Nutrient Requirements of Dairy Cattle. 7th Rev. Ed. Natl. Acad. Press, Washington, DC.

Pecsok, S. R., M. L. McGilliard, and R. L. Nebel. 1994. Conception rates. 1. Derivation and estimates for effects of estrus detection on cow profitability. J. Dairy Sci. 77:3008-3015.

Silva del Río, N., S. Stewart, P. Rapnicki, Y. Chang, and P. Fricke. 2007. An observational analysis of twin births, calf sex ratio, and calf mortality in Holstein dairy cattle. J. Dairy Sci. 90:1255-1264.

Skidmore, A. L. 1990. Development of a simulation model to evaluate effectiveness of dairy herd management. PhD Diss. Cornell University, Ithaca, NY.

VanRaden, P. M., and J. B. Cole. 2014. Lifetime Net Merit 2014. USDA. Accessed Jul. 3, 2017. http://aipl.arsusda.gov/reference/ nmcalc-2014.htm.

Willshire, J., and N. Bell. 2009. An economic review of cattle lameness. Cattle Pract. 17:136-141.

\section{APPENDIX}

Table A1. Input assumptions and resulting simulated distributions of values used in the treatment module of a stochastic simulation model developed to estimate the cost per case of 3 foot disorders

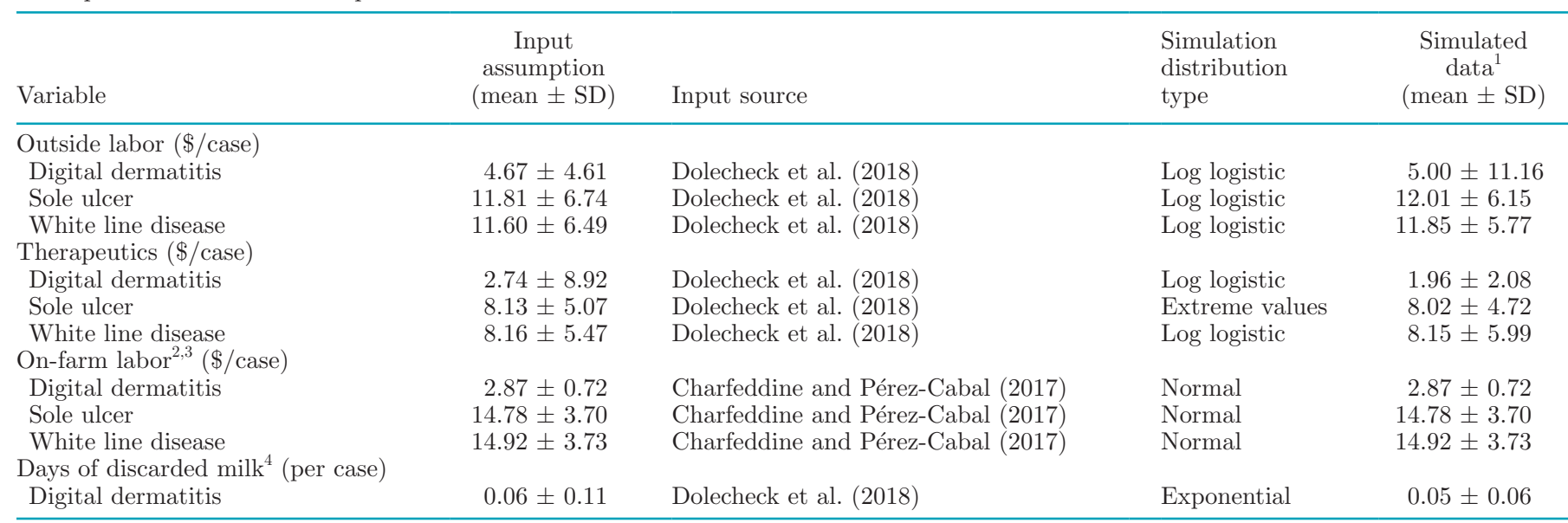

${ }^{1} \mathrm{n}=1,000$ iterations.

${ }^{2}$ Input source only reported a mean; the SD was calculated as a $10 \%$ coefficient of variation from the mean.

${ }^{3}$ The input assumption source reported on-farm labor for mild and severe cases of each disorder. For this study, on-farm labor costs for each disorder were calculated by weighting the value reported for mild cases by the incidence of mild cases observed in Charfeddine and Pérez-Cabal (2017) and the value reported for severe cases by the incidence of severe cases observed in the same study.

${ }^{4}$ An assumption was made that the percentage of cases requiring milk discard would be identical to the percentage of severe cases reported by Charfeddine and Pérez-Cabal (2017); on average, less than $1 \mathrm{~d}$ of discarded milk was necessary per case. 
Table A2. Input assumptions and resulting simulated distributions of values used in the milk loss module of a stochastic simulation model developed to estimate the cost per case of 3 foot disorders ${ }^{1}$

\begin{tabular}{|c|c|c|}
\hline Variable & $\begin{array}{l}\text { Input assumption } \\
\quad(\text { mean } \pm \mathrm{SE})\end{array}$ & $\begin{array}{c}\text { Simulated data } \\
(\text { mean } \pm \mathrm{SD})\end{array}$ \\
\hline \multicolumn{3}{|l|}{ Digital dermatitis } \\
\hline \multicolumn{3}{|l|}{ Primiparous (ECM kg lost/d) } \\
\hline 28 to $15 \mathrm{~d}$ before incidence & 0 & 0 \\
\hline 14 to $1 \mathrm{~d}$ before incidence & $-0.02 \pm 0.08$ & $-0.06 \pm 0.05$ \\
\hline 1 to $14 \mathrm{~d}$ after incidence & $-0.10 \pm 0.32$ & $-0.26 \pm 0.19$ \\
\hline$\geq 15 \mathrm{~d}$ after incidence & $-0.04 \pm 0.07$ & $-0.07 \pm 0.05$ \\
\hline \multicolumn{3}{|l|}{ Multiparous (ECM kg lost/d) } \\
\hline 28 to $15 \mathrm{~d}$ before incidence & $-0.58 \pm 0.24$ & $-0.59 \pm 0.25$ \\
\hline 14 to $1 \mathrm{~d}$ before incidence & $-0.86 \pm 0.23$ & $-0.86 \pm 0.24$ \\
\hline 1 to $14 \mathrm{~d}$ after incidence & $-0.88 \pm 0.25$ & $-0.91 \pm 0.24$ \\
\hline$\geq 15 \mathrm{~d}$ after incidence & $-0.53 \pm 0.22$ & $-0.53 \pm 0.23$ \\
\hline \multicolumn{3}{|l|}{ Sole ulcer } \\
\hline \multicolumn{3}{|l|}{ Primiparous (ECM kg lost/d) } \\
\hline 28 to $15 \mathrm{~d}$ before incidence & $-0.78 \pm 0.37$ & $-0.80 \pm 0.37$ \\
\hline 14 to $1 \mathrm{~d}$ before incidence & $-0.48 \pm 0.36$ & $-0.55 \pm 0.31$ \\
\hline 1 to $14 \mathrm{~d}$ after incidence & $-0.78 \pm 0.38$ & $-0.78 \pm 0.39$ \\
\hline$>15 \mathrm{~d}$ after incidence & $-0.96 \pm 0.42$ & $-1.02 \pm 0.39$ \\
\hline \multicolumn{3}{|l|}{ Multiparous (ECM kg lost/d) } \\
\hline 28 to $15 \mathrm{~d}$ before incidence & $-1.31 \pm 0.18$ & $-1.31 \pm 0.19$ \\
\hline 14 to $1 \mathrm{~d}$ before incidence & $-1.62 \pm 0.18$ & $-1.62 \pm 0.19$ \\
\hline 1 to $14 \mathrm{~d}$ after incidence & $-1.21 \pm 0.19$ & $-1.21 \pm 0.20$ \\
\hline$\geq 15 \mathrm{~d}$ after incidence & $-1.00 \pm 0.21$ & $-1.00 \pm 0.22$ \\
\hline \multicolumn{3}{|l|}{ White line disease } \\
\hline \multicolumn{3}{|l|}{ Primiparous (ECM kg lost/d) } \\
\hline 28 to $15 \mathrm{~d}$ before incidence & $-0.49 \pm 0.44$ & $-0.61 \pm 0.36$ \\
\hline 14 to $1 \mathrm{~d}$ before incidence & $-0.77 \pm 0.41$ & $-0.80 \pm 0.41$ \\
\hline 1 to $14 \mathrm{~d}$ after incidence & $-0.61 \pm 0.44$ & $-0.68 \pm 0.39$ \\
\hline$\geq 15 \mathrm{~d}$ after incidence & $-0.33 \pm 0.48$ & $-0.52 \pm 0.34$ \\
\hline \multicolumn{3}{|l|}{ Multiparous (ECM kg lost/d) } \\
\hline 28 to $15 \mathrm{~d}$ before incidence & $-1.34 \pm 0.22$ & $-1.34 \pm 0.23$ \\
\hline 14 to $1 \mathrm{~d}$ before incidence & $-1.27 \pm 0.22$ & $-1.27 \pm 0.23$ \\
\hline 1 to $14 \mathrm{~d}$ after incidence & $-0.86 \pm 0.23$ & $-0.86 \pm 0.24$ \\
\hline$\geq 15 \mathrm{~d}$ after incidence & $-0.40 \pm 0.25$ & $-0.45 \pm 0.23$ \\
\hline
\end{tabular}

${ }^{1}$ Input assumptions were taken from Charfeddine and Pérez-Cabal (2017) and used in PERT (program evaluation and review technique) distributions to calculate the simulated data ( $\mathrm{n}=1,000$ iterations).

${ }^{2}$ The input assumption source reported milk loss for mild and severe cases of each disorder. For this study, the milk loss for each disorder was calculated by weighting the value reported for mild cases by the incidence of mild cases observed in Charfeddine and Pérez-Cabal (2017) and the value reported for severe cases by the incidence of severe cases observed in the same study.

${ }^{3}$ Zero indicates that the value reported by the input source was positive (indicating an increase in milk yield); positive values were adjusted to 0 (i.e., no change in milk production).

Table A3. Input assumptions and resulting simulated distributions of values used in the days open module of a stochastic simulation model developed to estimate the cost per case of 3 foot disorders ${ }^{1}$

\begin{tabular}{lcc}
\hline Increase in days open $(\mathrm{d})$ & $\begin{array}{c}\text { Input assumption }{ }^{2,3} \\
\text { [mean (minimum-maximum) }\end{array}$ & $\begin{array}{c}\text { Simulated data } \\
\text { (mean } \pm \text { SD) }\end{array}$ \\
\hline Digital dermatitis & $0.0(0.0-4.3)$ & $0.7 \pm 0.6$ \\
Sole ulcer & $2.8(0.0-8.4)$ & $3.3 \pm 1.6$ \\
White line disease & $3.4(0.0-8.9)$ & $3.7 \pm 1.7$
\end{tabular}

${ }^{1}$ Input assumptions were taken from Charfeddine and Pérez-Cabal (2017) and used in PERT (program evaluation and review technique) distributions to calculate the simulated data ( $\mathrm{n}=1,000$ iterations).

${ }^{2}$ The input assumption source reported extended days open for mild and severe cases of each disorder. For this study, the extended days open for each disorder was calculated by weighting the value reported for mild cases by the incidence of mild cases observed in Charfeddine and Pérez-Cabal (2017) and the value reported for severe cases by the incidence of severe cases observed in the same study.

${ }^{3}$ If parameters (mean, minimum, or maximum) reported by the input source were positive (indicating an improvement in reproductive performance), they were adjusted to 0 (i.e., no change in days open). 
Table A4. Input assumptions and resulting simulated distributions of hazard ratios used in the culling module of a stochastic simulation model developed to estimate the cost per case of 3 foot disorders ${ }^{1}$

\begin{tabular}{|c|c|c|c|c|c|}
\hline Disorder and data type & $\begin{array}{l}\text { Incidence } \\
\text { timing }\end{array}$ & \multicolumn{4}{|c|}{ Time interval of culling } \\
\hline \multirow[t]{4}{*}{ Input assumptions [mean (95\% CI)] } & $\leq 60$ & $0.4(0.0-2.5)$ & $0.9(0.3-2.8)$ & $1.4(0.6-2.9)$ & $0.8(0.3-2.1)$ \\
\hline & $\overline{61}$ to 120 & & $0.7(0.1-5.4)$ & $0.5(0.2-1.7)$ & $0.9(0.4-1.9)$ \\
\hline & 121 to 240 & & & $0.3(0.0-2.2)$ & $0.7(0.3-1.9)$ \\
\hline & $>240$ & & & & $2.1(0.8-5.2)$ \\
\hline \multirow{2}{*}{ Simulated data $($ mean $\pm \mathrm{SD})$} & 121 to 240 & & & $1.6 \pm 0.5$ & $1.4 \pm 0.3$ \\
\hline & $>240$ & & & & $2.9 \pm 1.3$ \\
\hline \multicolumn{6}{|l|}{ Sole ulcer } \\
\hline \multirow[t]{4}{*}{ Input assumptions [mean (95\% CI)] } & $\leq 60$ & $2.0(0.9-4.3)$ & $2.4(1.2-5.0)$ & $2.6(1.4-4.9)$ & $1.3(0.5-3.1)$ \\
\hline & $\overline{6} 1$ to 120 & & $2.7(1.3-6.0)$ & $1.5(0.8-3.0)$ & $1.9(1.0-3.6)$ \\
\hline & 121 to 240 & & & $1.5(0.8-3.5)$ & $1.1(0.5-2.5)$ \\
\hline & $>240$ & & & & $2.2(0.7-7.1)$ \\
\hline
\end{tabular}

${ }^{1}$ Input assumptions were taken from Booth et al. (2004), who reported culling hazard ratios based on both time of disorder incidence and time of culling. Input assumptions were used in PERT (program evaluation and review technique) distributions to calculate the simulated data (n $=1,000$ iterations).

Table A5. Input assumptions and resulting simulated distributions of values used in the disease recurrence module of a stochastic simulation model developed to estimate the cost per case of 3 foot disorders ${ }^{1}$

\begin{tabular}{|c|c|c|}
\hline Item & $\begin{array}{l}\text { Input assumption } \\
\text { mean }\end{array}$ & $\begin{array}{l}\text { Simulated data } \\
\quad(\text { mean } \pm \mathrm{SD})\end{array}$ \\
\hline \multicolumn{3}{|c|}{ Relapse rate $^{3,4}$ (episodes per infected cow) } \\
\hline \multicolumn{3}{|l|}{ Digital dermatitis } \\
\hline Primiparous & 1.97 & $2.23 \pm 0.41$ \\
\hline Multiparous & 2.26 & $2.42 \pm 0.43$ \\
\hline \multicolumn{3}{|l|}{ Sole ulcer } \\
\hline Primiparous & 2.48 & $2.57 \pm 0.41$ \\
\hline Multiparous & 2.55 & $2.62 \pm 0.41$ \\
\hline \multicolumn{3}{|l|}{ White line disease } \\
\hline Primiparous & 2.56 & $2.62 \pm 0.40$ \\
\hline Multiparous & 2.70 & $2.72 \pm 0.41$ \\
\hline \multicolumn{3}{|l|}{ Disorder length $^{5}(\mathrm{mo})$} \\
\hline Digital dermatitis & $3.64(2.66-4.79)$ & $3.67 \pm 0.40$ \\
\hline Sole ulcer & $2.50(1.37-4.00)$ & $2.56 \pm 0.50$ \\
\hline White line disease & $4.20(2.28-6.41)$ & $4.25 \pm 0.78$ \\
\hline \multirow{2}{*}{\multicolumn{3}{|c|}{$\begin{array}{l}{ }^{1} \text { Input assumptions for relapse rates were collected from Charfeddine and Pérez-Cabal (2017) and used in } \\
\text { PERT (program evaluation and review technique) distributions to calculate the simulated data. Input assump- } \\
\text { tions for disorder length were collected from Bruijnis et al. (2010) and used in PERT distributions to calculate } \\
\text { the simulated data. } \\
{ }^{2} \mathrm{n}=1,000 \text { iterations. }\end{array}$}} \\
\hline & & \\
\hline \multicolumn{3}{|c|}{$\begin{array}{l}{ }^{3} \text { The input assumption source reported disorder relapse rates for mild and severe cases of each disorder sepa- } \\
\text { rately. For this study, the disorder relapse rate for each disorder was calculated by weighting the value reported } \\
\text { for mild cases by the incidence of mild cases observed in Charfeddine and Pérez-Cabal (2017) and the value } \\
\text { reported for severe cases by the incidence of severe cases observed in the same study. }\end{array}$} \\
\hline \multicolumn{3}{|c|}{$\begin{array}{l}{ }^{4} \text { The input assumption source only reported mean relapse rates. Relapse rate minimum and maximum values } \\
\text { were assumed the same for all disorders for stochastic modeling purposes. Minimum and maximum were set to } \\
1.50 \text { and } 4.00 \text { based on values reported by Ettema et al. (2010). }\end{array}$} \\
\hline \multicolumn{3}{|c|}{$\begin{array}{l}{ }^{5} \text { Mean (5th-95th percentile); the input assumption source reported disorder length for subclinical and clinical } \\
\text { cases of each disorder. For this study, the disorder length for each disorder was calculated by weighting the } \\
\text { value reported for subclinical cases by the incidence of mild cases observed in Charfeddine and Pérez-Cabal } \\
\text { (2017) and the value reported for clinical cases by the incidence of severe cases observed in the same study. }\end{array}$} \\
\hline
\end{tabular}

